\title{
Ensayo sobre la pandemencia: cuando los personajes y microbios de la ciencia ficción salen de la película
}

\author{
Essay on Pandementia: when the characters and \\ microbes of science fiction jump off the screen and \\ invade the planet
}

${ }^{1}$ Médico. Doctor en Salud Pública. Investigador, Departamento de Epidemiologia e Métodos Quantitativos em Saúde, Escola Nacional de Saúde Pública Sergio Arouca, Fundação Oswaldo Cruz, Río de Janeiro, Brasil. $\square$ (iD
RESUMEN Este ensayo crítico acerca de las declaraciones sobre la técnica y la vida en el planeta COVID-19 propone una reflexión ético-filosófica de los efectos de la pandemia. Trata de entender, atribuir significados y criticar las referencias a la pandemia, especialmente en Brasil, en momentos especialmente dramáticos, debido a la sinergia entre la grave enfermedad que afecta al país y al planeta, y un gobierno que se destaca por su gigantesca incapacidad para hacer frente a la calamidad. Este texto fue escrito en el periodo de "cuarentena" brasileña, desde mediados de marzo hasta fines de abril de 2020. Es un momento en el que los hechos nos golpean y no dejan de atormentarnos, y se vive a diario bajo el terrible dominio de esta pandemia. Así, este texto se caracteriza por estar elaborado en medio de un contexto social marcado por los esfuerzos de control y atención de la salud de los afectados, a pesar del complejo marco político actual y de las profundas dificultades económicas del país.

PALABRAS CLAVES COVID-19; Pandemias; Riesgo a la Salud; Epidemiología; Enfermedades Transmisibles.

ABSTRACT This essay intends to carry out an ethical and philosophical reflection on the effects of the emergency contingencies of the COVID-19 pandemic. With a focus on Brazil, it seeks to understand, critique, and attribute meaning to references to the pandemic, in particularly dramatic moments brought about by the synergy produced between the serious disease affecting the country and the world and a government that stands out for its remarkable unwillingness and inability to deal with this calamity. This text was written during the Brazilian "quarantine," which lasted from mid-March to late April, 2020. During this period, we were bombarded by facts that never ceased to haunt us, and lived each day under the terrible dominion of the pandemic. Therefore, this text was written in the midst of a social context marked by control efforts, with great attention directed at the health of those affected, despite the complex political framework and serious economic difficulties facing the country.

KEY WORDS COVID-19; Pandemics; Health Risks; Epidemiology; Communicable Diseases. 


\section{INTRODUCCIÓN}

En primer lugar, para justificar el título del artículo, si bien no es necesario explicar el sentido de la palabra "pandemencia", nuestra intención apunta a sintetizar las causas y los efectos que el COVID-19 ha generado en la forma de vida de las personas a escala planetaria, pero sobre todo en Brasil. Ciertamente más significativa es la apropiación de la expresión "Ensayo sobre...", inspirada en la obra distópica Ensayo sobre la ceguera de José Saramago, y la alusión a La rosa púrpura de El Cairo, película de Woody Allen de 1985, en la que los personajes salen de la pantalla y comienzan a interactuar con los espectadores.

Al momento de escribir este texto, estamos a fines de la segunda mitad de abril de 2020, un año para recordar. En esta instancia, estamos siendo atropellados por hechos que nos persiguen día a día. Vivimos bajo el terrible yugo de esta pandemia que nos afecta de un modo insano, demente (en el sentido específico de la locura). Por lo tanto, este texto se caracteriza por estar ciertamente aturdido, ya que se ha elaborado en medio de la desolación social causada por las medidas de distanciamiento y de la invasión de información que recibimos a diario.

No parece apropiado o moralmente razonable identificar una pandemia con algo pintoresco. Aun así, se puede especular que estamos en un proceso de cambio en las formas de designar las enfermedades. Parece que paulatinamente hay enfermedades que se denominan según criterios relacionados con algunos de los nombres codificados en inglés como si fueran "marcas" en forma de acrónimos, como en el caso del SARS (severe acute respiratory syndrome), de MERS (Middle East respiratory syndrome), o COVID-19 (Coronavirus disease 2019).

\section{DIMENSIONES SIMBÓLICAS RELACIONADAS CON LA PANDEMIA}

Hay aspectos alegóricos que subrayan algunas dimensiones de esta calamitosa situación.
Como se sabe, los coronavirus están compuestos de una tira de ácido ribonucleico $(A R N)$, y este material genético está rodeado por una membrana salpicada de pequeñas proteínas en forma de "spike", es decir, "espinas". Bajo un microscopio, estas proteínas se encuentran en un anillo alrededor de la parte superior del virus, que recibe el nombre de "corona". Cuando el virus ingresa al cuerpo, estas proteínas se unen a las células huésped, y el virus inyecta este ARN en el núcleo de la célula y se apropia de sus máquinas de replicación para reproducir más virus ${ }^{(1)}$.

Ahora bien, hay al menos una coincidencia en esta forma de denominar el virus: por un lado, una referencia inevitable a las coronas hechas con joyas que distinguen a reyes, reinas y sus poderes aristocráticos; $y$, por otro, la referencia al salvador en las religiones cristianas que se vio obligado a usar una corona de espinas en su crucifixión. Esta metáfora contiene una referencia al poder y otra a la subyugación y el martirio. Ambas perspectivas confluyen para destacar los efectos infecciosos y virulentos del COVID-19. Por un lado, su gran poder en términos de difusión y, por otro, su capacidad de infligir sufrimiento a quienes pierden seres queridos, solo que, en este caso, sin posibilidad de resurrección. Hay una santa católica consagrada como Santa Corona, que fue martirizada por los romanos y enterrada en la ciudad de Anzu en el siglo IX. Era una cristiana que murió bajo el emperador Marco Aurélio en el año 165 d.C., y durante siglos ha sido una de las santas patronas de las epidemias y pandemias ${ }^{(2)}$.

Aun así, no es posible relacionar las epidemias de enfermedades transmisibles en la actualidad con las pestes de la antigüedad. Obviamente, no había conocimientos específicos en término epidemiológicos ni terapéuticos para superar estos acontecimientos calamitosos. Con los avances científicos, se pueden tener recursos vinculados con el desarrollo de tecnologías, medicamentos, vacunas y prácticas preventivas para hacer frente a la propagación epidémica de enfermedades infecciosas.

El aumento de la longevidad en ciertos grupos sociales sería solo un indicador de estos avances. Pero ¿de qué sirve esto si la 
mayor letalidad del COVID-19 es precisamente en los grupos de mayor edad? Las formas de organización política, económica y social adoptadas por el modo de producción industrial que reemplazó al feudalismo indudablemente dieron lugar a muchos avances en diferentes conjuntos sociales. Sin embargo, la distribución de estos beneficios fue desigual y, además, no pudo evitar la vuelta de signos y síntomas reprimidos en la sociedad capitalista, como si esta forma de organización social fuese incapaz de evitar la emergencia de algo podrido en su interior.

\section{Salud versus economía: contribuciones filosóficas a los enfrentamientos sobre la atribución de significados ideológicos a la pandemia}

Es importante señalar que, antes del COVID-19, el neoliberalismo ya evidenciaba una epidemia causada por el virus de la precariedad. Un mal social que admitió, mucho antes de la declaración de un estado de alarma, su propio régimen de emergencia para ciertos sectores considerados socialmente excedentes o marginados: grupos desprotegidos compuestos por pobres, desempleados, migrantes, trabajadores domésticos, refugiados, indocumentados, etc. Las opresiones de género, clase y raza son fundamentales aquí( ${ }^{3)}$.

En este sentido, vale la pena recuperar los comentarios de Judith Butler ${ }^{(4)}$ sobre los efectos de la pandemia en las ideas de igualdad, interdependencia global y obligaciones mutuas. Las formas en que actúa el virus y sus efectos en los grupos humanos destacan nuestra precariedad vital. Al mismo tiempo, ciertos países han fracasado en prepararse con la debida anticipación en forma eficaz, y la implementación de medidas relacionadas con el cierre de fronteras ha sido subrayada como posturas xenófobas. Por todos lados, vemos la acción de emprendedores ansiosos por lucrar con el sufrimiento planetario. Como era de esperar, la máquina capitalista produce desequilibrios y desarrolla modos de mantener sus poderes aún con quienes son los sectores afectados por la pandemia. Esto muestra la singularidad con la que se mantienen desigualdades radicales, que incluyen el nacionalismo, la supremacía blanca, la violencia contra las mujeres y contra las poblaciones queer $y$ trans ${ }^{(4)}$.

El profesor John loannidis, epidemiólogo y codirector del Centro de Innovación y Metainvestigación de la Universidad de Stanford es citado por considerar los datos existentes "muy poco confiables". Aun así, incluso teniendo en cuenta los sesgos de quien escribe, parece que -excepto por malentendidos- este epidemiólogo desarrolla análisis sujetos a sesgos conservadores ${ }^{(5)}$.

En Brasil, hubo un pronunciamiento mesiánico de Bolsonaro que, sin modestia, sostuvo que la prioridad es privilegiar la actividad económica, porque si esta se ve comprometida, la situación será aún más perjudicial para la gente que la pandemia. Este presidente atroz muestra su faceta más oscura sin modestia (como de costumbre). Opta por liderar un grupo de negacionistas que están tomando Brasil a pasos agigantados ${ }^{(6)}$.

La revista The Lancet Public Health, en un editorial publicado el 28 de marzo de 2020 y titulado "COVID-19: aprender de la experiencia", proporciona una visión general de la evolución de la enfermedad en el mundo. El "lockdown", considerado al inicio de la pandemia como una política demasiado restrictiva, se habría convertido en un lugar común. Aun así, muchas naciones no estarían siguiendo las recomendaciones de la Organización Mundial de la Salud para contener la pandemia, como las pruebas ampliadas, la cuarentena, el seguimiento de contactos y la distancia social. La tensión entre economía y salud pública también aparece en The Lancet Public Health, en un comentario crítico del editor Robert Horton ${ }^{(7)}$. Allí se destaca que, en cualquier libro de texto de economía con postulados neoliberales, es previsible un énfasis en la importancia de preservar los mercados, la eficiencia, el precio y la utilidad, el beneficio y la libre competencia. Estas categorías definen inexorablemente modelos que limitan cualquier expectativa hacia un sistema de salud pública satisfactorio. Cuando las herramientas de gestión que entran en 
juego tienen la intención de evaluar los costos y beneficios de las inversiones y los rendimientos respectivos como pautas que guían las decisiones, algo relevante se pierde o desfigura. Parece haber un diseño intencional de privatización de lo público.

Es inevitable pensar que la economía neoliberal enmarca la forma en que pensamos y actuamos. Entroniza el libre comercio, la privatización, el estado mínimo y la reducción del gasto público en las áreas sociales y de salud. En resumen, una economía marcada por una filosofía utilitaria no tiene otra salida: cínicamente articula sus premisas supuestamente bien intencionadas, apoyadas en conceptos elevados como la felicidad y el placer.

La inevitable mención al cinismo también la hace el incisivo Demetrio Magnoli para el caso brasileño. A pesar de su extensión, vale la pena citarlo:

Las medidas económicas anunciadas por el gobierno implican pérdidas colosales de empleos e ingresos, que se distribuyen de manera perversamente desigual, descargando sus costos sobre las espaldas de los más débiles. La ecuación cínica que los guía tiene dos partes incongruentes. La primera, se expresa en el cierre de comercio y los servicios, suspendiendo así las reglas de la economía de mercado. La segunda, se manifiesta en las nuevas líneas de crédito, se basa precisamente en esas reglas suspendidas. Es hora de exigir consistencia: la factura debe llegar a los privilegiados que tienen balcones frente al mar. La economía nacional de emergencia, en lugar de una economía de mercado, significa: 1) garantizar el salario mínimo para los trabajadores informales; 2) prohibir legalmente los despidos durante la emergencia, que durará más allá del aislamiento; 3) garantizar la supervivencia de las pequeñas y medianas empresas que se cierran mediante préstamos a largo plazo respaldados por intereses negativos. Ahora el gobierno no inventa el dinero. El estallido de la deuda pública que generarán estas políticas se pagará con inflación o austeridad extrema, es decir, lo pagarán los pobres. La alternativa se encuentra en un impuesto de emergencia sobre grandes fortunas, bancos y altos activos financieros, además de la reducción temporal de los altos salarios de los funcionarios. Humanismo, ok, pero sin vista al mar. ${ }^{(8)}$

También es necesario considerar la carga metafórica en el uso de la idea de "cuarentena" utilizada por los epidemiólogos de enfermedades infecciosas del Imperial College. Como se informó ampliamente, ellos fueron los que desarrollaron modelos para verificar la efectividad comparativa de las estrategias de mitigación/supresión como modelos para hacer frente a la pandemia. No tiene nada que ver con el procedimiento que se conoce desde el siglo XV. Estrictamente hablando, el término se puede usar si se establece un caso de contacto de un individuo con alguien que haya dado positivo por el virus. Dentro del enfoque de supresión, incluso con la posibilidad de contaminación, la perspectiva es que esta iniciativa, en forma agregada, reduzca el contagio, a fin de disminuir la alta tasa de reproducción de SARS-CoV-2. El propósito es evitar un aumento exponencial en el número de casos, lo que podría conducir a saturar la demanda de recursos tecnológicos e incluso de personal relacionados con la atención médica y hospitalaria. Por otro lado, el argumento de consecuencias económicas y sociales mucho peores que la enfermedad misma evoca las posiciones de grupos que, de hecho, parecen estar más preocupados por sus propias finanzas que por la magnitud de los daños a la salud de la población en general.

En este sentido, Hélio Beltrão, presidente del Instituto Von Mises de Brasil, publicó en el diario Folha de São Paulo la siguiente crítica al gobernador de San Pablo, João Dória:

El buen gestor [...] sabe que el bloqueo de la actividad económica en tiempos de pandemia no debe prescindir de una base científica sólida. Esta base estuvo ausente en el infame "paper" del Imperial College, adoptado como referencia por varios países y cuya adaptación a Brasil predijo 1 millón de muertes si no 
se efectuaba la cuarentena. En medio de numerosos errores metodológicos, el "paper" ignoró fatalmente los costos involucrados en la medida propuesta. La cuarentena se basó en una opinión personal y no en ensayos clínicos aleatorizados, regla de oro de la ciencia médica. ${ }^{(9)}$

Resulta irrazonable atribuir errores metodológicos al "paper infame" del Imperial CoIlege. Estrictamente hablando, postula un modelo matemático relevante para hacer frente a una situación de emergencia pandémica provocada por un virus desconocido para el que no hay terapia o vacuna. Por lo tanto, no hay forma de desarrollar ensayos clínicos aleatorios previos. Sostener que el modelo fue el resultado de una opinión personal es, como mínimo, ingenuo. El tema principal se centró, fundamentalmente, en tratar de contener la pandemia más allá de los costos económicos. Dadas las circunstancias de emergencia, el grupo de Neil Ferguson no está obligado a desarroIlar modelos matemáticos sobre "los costos involucrados en el cierre de las actividades sociales y económicas".

Parecería que Beltrão opina sin tener demasiado conocimiento sobre el tema. Supone que la epidemiología subyacente a los modelos matemáticos pudiera resolver sus expectativas de evaluar el tamaño aproximado de las pérdidas humanas para cada nación y, sobre todo, el tiempo de suspensión de las actividades económicas. Sin embargo, esta pregunta también cae dentro de una visión más instrumental de la epidemiología como si fuera capaz de redimir los problemas de salud: en definitiva, una epidemiotopía.

En cierto modo, esto puede ser parcialmente cierto si miramos las enfermedades desde un punto de vista naturalista, es decir, concebir la salud como una condición que depende solo de hechos naturales (biológicos o físicos) mensurables y sujetos a medidas de control adecuadas. El punto de vista naturalista requiere de la disponibilidad de recursos tecnológicos que, por ejemplo, varios países africanos pobres no pueden disponer.
Por otro lado, una perspectiva normativista reduce las enfermedades a su adecuación a parámetros clasificatorios, desdeñando aspectos económicos políticos y culturales insoslayables para su tratamiento. Sin embargo, en el contexto de una pandemia, puede incluso ser imposible elegir los enfoques convenientes para comprender y para actuar.

De todos modos, es necesario ponderar las posibilidades de sustentar la "cuarentena" más allá de cierto período de tiempo. Las singularidades sociales, culturales, políticas, económicas, en términos generales y, específicamente, los modos de organización y los recursos de los sistemas de salud de los países pueden tener diferentes capacidades para responder a una situación de tal gravedad.

Hablando en términos generales, las poblaciones de ciertos países pueden adoptar los comportamientos preventivos propuestos, como el distanciamiento social, de un modo más o menos "disciplinado" que otros. En el caso de un país marcado por una inmensa inequidad como Brasil, los regímenes de cuarentena pueden ser viables, en gran medida, con grupos socioeconómicamente privilegiados. Pero, aun así, ¿cuánto tiempo pueden las personas y sus formas de vida mantenerse bajo este régimen? Por otro lado, es imperativo que las autoridades sanitarias cuenten con apoyo político, recursos financieros, humanos, técnicos y autonomía para actuar con eficacia. El ejemplo más sorprendente puede ser Alemania. Es fundamental tener en cuenta que, en muchos rincones de este mundo, es destacable tanto el grado de precariedad de grandes contingentes de la población como las capacidades de respuesta institucional, sin mencionar el desprecio abominable de gobernantes espurios. En estas situaciones, existe una alta probabilidad de fracaso de las medidas de cuarentena y el uso de máscaras con la inevitable exposición a la infección. Sobre todo, uno debe considerar la velocidad con la que tanto el sistema de salud como el aparato funerario colapsan con sus atroces resultados. 


\section{El subregistro y sus consecuencias perjudiciales en la aplicación de medidas de aislamiento social}

De acuerdo con la epidemióloga Ana Cristina Marques Martins y el epidemiólogo Marcus Vinicius de Azevedo Braga, existe un subregistro de casos de COVID-19 motivado por la dificultad de realizar diagnósticos a partir de testeos parciales en el contexto de una alta incidencia de la enfermedad. El modo de superar estas dificultades es la búsqueda activa de casos sospechosos, la implementación de reglas claras y explícitas de diagnóstico, el uso de tecnología de la información y la utilización de pruebas confiables ${ }^{(10)}$.

Es esencial considerar las posibilidades de suspender las medidas de aislamiento social en términos prospectivos. En este sentido, son relevantes las conclusiones de un estudio realizado por el grupo dirigido por el epidemiólogo Marc Lipsitch, publicado en la revista Science. La incidencia total de la enfermedad COVID-19 en los próximos cinco años dependerá críticamente de la circulación regular, después de la onda pandémica inicial. Esto, a su vez, depende principalmente de la duración de la inmunidad a la infección por SARS-CoV-2. La intensidad y el momento de los brotes pandémicos y pospandémicos se relacionan con la época del año en que se establezca la infección generalizada por SARS-CoV-2 y, en menor medida, con la magnitud de la variación estacional en la transmisibilidad y el nivel de inmunidad cruzada que existe entre los coronavirus.

Es necesario medir hasta qué punto el distanciamiento social es capaz de reducir las infecciones por SARS-CoV-2, que sobrecargan los sistemas de salud. El distanciamiento altamente efectivo podría reducir la incidencia de SARS-CoV-2 lo suficiente como para permitir una estrategia basada en el rastreo de casos y la continuidad de la cuarentena como en Corea del Sur y Singapur. Esfuerzos menos efectivos pueden resultar en una epidemia prolongada de un solo pico, con la consecuente presión sobre el sistema de salud y la necesidad de continuidad con el distanciamiento, cuya aceptación social puede ser variada.
El distanciamiento intermitente puede ser necesario hasta 2022, a menos que la capacidad de atención crítica se incremente sustancialmente o se disponga de un medicamento o de una vacuna. Indudablemente, el distanciamiento prolongado, incluso si es intermitente, puede tener consecuencias económicas, sociales y educativas profundamente negativas.

Según Lipsitch y su grupo de trabajo, el objetivo de modelar estas políticas no es sinónimo de respaldarlas, sino anticipar posibles trayectorias de la epidemia bajo enfoques alternativos e identificar intervenciones complementarias. Entre ellas se encuentran ampliar la cantidad de unidades de terapia intensiva, el tratamiento para reducir la demanda de estos servicios y el estímulo de ideas innovadoras para controlar la pandemia a largo plazo. También subrayan no haber tomado una posición sobre la conveniencia de estos escenarios, dada la carga económica que pueden imponer, y sus potenciales efectos catastróficos sobre el sistema de salud, si la distancia es ineficaz y/o insostenible. El modelo tendrá que adaptarse a las condiciones locales y actualizarse a medida que se disponga de datos más precisos. Se necesitan urgentemente estudios serológicos longitudinales para determinar el alcance y la duración de la inmunidad al SARS-CoV-2, y además mantener la vigilancia epidemiológica en los próximos años para anticipar la posibilidad de resurgimiento de nuevos brotes ${ }^{(11)}$.

Una cuestión crucial es identificar el momento en el que es posible reducir las medidas de distanciamiento social. Paradójicamente, en países en los que la transmisión del coronavirus se ha acelerado, suspender las medidas de confinamiento antes de tiempo puede imposibilitar el testeo para combatir la pandemia. Esto se debe a que a través del conocimiento de la curva de incidencia de casos se puede evaluar el grado de transmisibilidad de la enfermedad, dato imprescindible para asegurar que la flexibilización de la cuarentena no dispare la cantidad de casos.

Además, en términos esquemáticos, es necesario tener en cuenta la posibilidad de cuatro "olas" que pueden impactar en la demanda de los servicios de salud: 1) atención 
de personas debido a COVID-19; 2) falta de personal y equipo para la atención de urgencias; 3) aumento de hospitalizaciones por enfermedades crónicas no monitoreadas; 4) trauma psicológico y aumento de la enfermedad mental ${ }^{(12)}$.

Ahora, en el caso de Brasil, el brote pandémico puede presentar variaciones en su posible aceleración en diferentes ciudades y estados. También hay señales de incertidumbre en cuanto al grado de subregistro que pueda existir. A esto hay que agregarle el ímpetu del brote de bolsonárie y sus consecuencias necropolíticas en la generación de daños y pérdidas sociales.

Según los European Centre for Disease Prevention and Control (ECDC) y la Organización para la Cooperación y el Desarrollo Económico (OCDE), los test requieren planificación y una alta inversión en equipos, reactivos y mano de obra, algo que puede dificultar su uso a gran escala en países que han pasado la primera fase de la epidemia, cuando los casos aún son esporádicos. Pero independientemente de la etapa en la que se adopte, la estrategia requiere evaluar a casi todos los que tienen síntomas similares a la gripe, localizar a quienes dieron resultados positivos para garantizar que estén en cuarentena y rastrear entre el $70 \%$ y el $90 \%$ de sus contactos, que también deben ser testeados.

\section{¿HUMANISMO VERSUS UTILITARISMO?}

Luiz Felipe Pondé -médico, doctor en filosofía de la Universidad de San Pablo, ensayista y escritor- se dedica desde hace tiempo a tratar en sus discursos y escritos diversos temas de actualidad. Su propósito es presentar en un formato accesible temas filosóficos y éticos a un público general. Sin embargo, esto puede ser bastante complejo. Como regla general, apela al uso de una retórica capaz de "traducir" y, eventualmente, "simplificar" los problemas filosóficos, evitando apelar a conceptos complejos y utilizando alegorías y metáforas como recursos explicativos.
El 20 de abril de 2020, Pondé presentó un artículo periodístico en el que discute un supuesto malentendido entre las posiciones humanistas y utilitarias frente a las contingencias de COVID-19. El título "Humanismo, utilitarismo y terrorismo" es menos esclarecedor que el subtítulo "La afirmación 'las vidas hacen a la economía y no al contrario' parece de Disneylandia" (es decir, no coincide con pensamientos más elaborados que aquellos producidos en situaciones de ocio para aqueIlos que tienen acceso al ocio). El texto destaca una "confrontación" engañosa entre el mantenimiento de la vida ("humanismo") y la preservación de la "economía", que no sería una propuesta "humanista", por ubicar a las pérdidas de capital que por sobre las pérdidas humanas.

Con su habitual lenguaje cáustico, Pondé hace una lectura de los significados que se estarían utilizando para comprender las medidas de contención epidémica en Brasil:

...el humanismo versus el utilitarismo es pura retórica barata, pero buena para polarizar el espacio político. Humanista, en el sentido utilizado en el contexto de esta epidemia, es valorar la vida por encima de todo. Como cada muerte es absoluta, el valor absoluto de la vida es incuestionable. Pero cuando un oportunista dice eso, su raciocinio se paraliza. Utilitarista, también en el sentido común con el que se utiliza en el contexto de la epidemia, es el inhumano que piensa en la economía y no reconoce el valor absoluto de la vida. Error: el utilitarismo no es deshumano. ${ }^{(13)}$

Es cierto que el término "humanismo" ha tenido diversos significados en su historia conceptual cuya riqueza no puede ser abordada en una columna periodística reducida. Aun así, es necesario destacar que hubo una proliferación de ideales humanos y de humanismos, como el cristiano, el socialista, el liberal, el existencialista, el científico, entre otros. Es pertinente considerar que algunas perspectivas humanistas abordan la idea como un concepto o como un método ${ }^{(14)}$. Pero la cuestión 
a considerar aquí es el uso del término "inhumano". La argumentación en este caso, puede extremar la simplificación. Esto es, alejarse del sustantivo "humano", que pone el foco en "la persona", "el individuo" o la sociedad y pasar al antónimo del adjetivo "humano". Y más aún: en este momento, presenta un fuerte argumento: "la realidad no cabe en esta oposición $^{\prime \prime(13)}$. Nuevamente encontramos un concepto ómnibus: "realidad", que al igual que "sociedad" y "vida", son categorías que generan discusiones y controversias en torno a sus significados. Además, de esto, se presenta el confinamiento como un ejemplo elocuente del "humanismo" que serviría para mantener el sistema de salud sin saturación, incluida la preservación de los trabajadores que allí se desempeñan.

De acuerdo con Pondé, este razonamiento es "claro como el cristal para cualquier persona capacitada en ética utilitaria"(13). Este "humanismo" al defender la vida como "vida desnuda" sería insatisfactorio. Sin embargo, es necesario referirse a una idea implícitamente redundante en la categoría de "humanismo humano" en esta discusión. $\mathrm{Y}$, por supuesto, también tenemos que considerar la afirmación por demás simplista de que:

...el utilitarismo es humanista, en el sentido filosófico del término: cree en la capacidad racional del ser humano para tomar decisiones que reduzcan el sufrimiento de las personas. ${ }^{(13)}$

Aquí el término "humanista" se confunde con la idea de racionalidad en términos de razón humanitaria. La institución de tal "racionalidad" que define al humanismo como reductor del sufrimiento humano es muy poco clarificador de sus supuestos ${ }^{(13)}$.

Este comentario nos permite introducir la relevancia de un enfoque más elaborado de ética utilitaria frente a las vicisitudes de COVID-19. Habermas, en una entrevista con Le Monde $^{(15)}$, señala que el "triage" -que puede producirse por la saturación de las unidades de cuidados intensivos de hospitales- obliga al trabajador de la salud a tomar decisiones trágicas, incluso inmorales. De este modo, se puede violar el principio de igualdad estricta en el tratamiento, más allá del estatus social, el origen, la edad, etc., o promover la tentación de privilegiar, por ejemplo, a las personas más jóvenes sobre las mayores. Ningún trabajador de la salud puede ocupar el lugar de árbitro de la vida y la muerte al "comparar" el "valor" de una vida humana con otra. Además: el vocablo "valor", que proviene de la esfera de la economía, propone una cuantificación desde la perspectiva del observador. Por otro lado, la deontología médica está en conformidad con la Constitución, postula el principio de imposibilidad de "elegir" una vida humana en detrimento de otra y, en situaciones que obligan a tomar decisiones trágicas, le dicta al trabajador de la salud guiar sus decisiones exclusivamente en las evidencias científicas disponibles.

Tal como se mencionó anteriormente, también es importante tratar los problemas técnicos y éticos vinculados a la lógica utilitaria de cálculo con el momento adecuado para poner fin a las medidas de confinamiento. Las entidades políticas deben resistir ubicarse en la posición de árbitro entre, por un lado, el daño económico o social y, por otro, las muertes prevenibles. Los derechos fundamentales prohíben a las instituciones estatales tomar cualquier decisión para dar cabida a la muerte de personas, aunque este no parece ser el caso de la mala gestión vigente en Brasil. Se pueden implementar criterios utilitarios para decidir quién vive y quién muere. En términos esquemáticos, el principio de utilidad, elemento principal de la teoría moral utilitaria, establece que la acción correcta es la que produce felicidad en los términos más amplios. John Stuart Mill adaptó la teoría de Jeremy Bentham y afirmó que la felicidad es placer y ausencia de dolor. Sin embargo, Mill aclaró que existen diversos placeres: los superiores serían los placeres del intelecto, mientas que los placeres inferiores serían los de los sentidos. Ahora, moralmente hablando, al utilitarista no solo le importa la cantidad de placer, sino también la calidad. Si aplicamos esta teoría a nuestras vidas, podríamos volvernos, quién sabe, más altruistas. Tal vez muchos de los problemas que enfrentamos podrían 
aliviarse, porque la felicidad de todos tendría el mismo valor. Los prejuicios y la discriminación no tendrían lugar, ya que cada individuo tendría el mismo valor en el cálculo de la felicidad producida por las acciones de todos.

Una objeción recurrente que se le hace a la perspectiva utilitarista es que podría quebrantar estándares de la justicia. Por ejemplo, imaginémonos como jueces en un pueblo pequeño. Alguien comete un delito $y$, como consecuencia de ello, se producen disturbios sociales que alteran la vida colectiva. Un hombre es apresado como sospechoso. Como jueces, no sabemos si cometió el crimen, pero sabemos que si condenamos a este hombre la ciudad se calmará y se restablecerá la paz. Por el contrario, si lo liberamos, se producirán aún más disturbios, con más daños para sus habitantes. El utilitarismo nos conduce a castigar a una persona aún sin saber si es culpable como en estas circunstancias.

Sabemos que está mal castigar a una persona inocente, pero para el utilitarista, lo único que importa es la ganancia neta de felicidad general. El utilitarismo parece requerir que se cometan acciones injustas en ciertas situaciones, y es por esto que es esencialmente defectuoso, como el capitalismo. Algunas cosas nunca deben hacerse, independientemente de las consecuencias positivas que puedan ocurrir en otra escala. Además, ¿cómo se define la felicidad para todos de manera sostenible? Basta contemplar las diferentes perspectivas sobre la felicidad social, o algo que disminuya los terrores de la infelicidad prevaleciente, para vislumbrar lo complejo que es responder a esta pregunta. Aun así, la racionalidad utilitaria predomina en nuestros diálogos políticos y morales. Las consecuencias de las medidas para contrarrestar los efectos de la pandemia deben ser consideradas, pero también debemos pensar en otros principios morales, otras virtudes relevantes, en los derechos humanos y en lo que todo esto dice sobre las elecciones y juicios que hacemos sobre nosotros. Las consecuencias son importantes, pero no son lo único que importa. La moralidad es más que las consecuencias de nuestras acciones ${ }^{(16)}$.
Ahora bien, como se mencionó anteriormente, hay una cuestión crucial que generalmente surge en situaciones calamitosas, como es el caso de la pandemia de COVID-19. La pandemia exige a los sistemas de salud acciones que, dadas las limitaciones en la disponibilidad de respiradores para el tratamiento hospitalario, no podrán satisfacer la totalidad de la demanda en forma simultánea. En este contexto ¿quién debería ser asistido y posiblemente salvado en primer lugar? Hay expertos en bioética dispuestos a proporcionar criterios para llegar a una elección basada en alguna noción orientadora de justicia. Antes de las limitaciones relacionadas principalmente con el número insuficiente de camas y aparatos de respiración mecánica vinculadas con la pandemia, existían protocolos sobre "quién vive y quién muere". ¿Cómo decidirán los médicos y los hospitales quién recibe un tratamiento y quién no? Los principios éticos para el "racionamiento" de los recursos sanitarios, desde una perspectiva "utilitaria" favorecen a aquellos que tienen una esperanza de vida más larga. Pero ¿qué significa una vida más larga? Parecería que desde esta perspectiva ciertos caminos ya tienen una mayor o menor probabilidad de éxito.

Maximizar imparcialmente la "felicidad" (o satisfacer las preferencias del consumidor, como si las personas con poder adquisitivo no fueran inducidas a esto), desde una perspectiva utilitarista, significa promover la mayor cantidad de "felicidad" a todos aquellos que se ven afectados de alguna manera por las decisiones de los médicos. Determinar quién va a recibir un respirador más allá de los afectos o los lazos de sangre que nos pueden unir a esa persona es un claro ejemplo de esto.

Ahora, uno de los problemas del utilitarismo es que postula la felicidad o placer (o más bien, deberíamos decir la supervivencia) como fin último de nuestras acciones. La acción correcta es identificada en función de las mejores consecuencias colectivas, definidas a su vez por una maximización "imparcial" de la felicidad de quien es elegido para no morir (y de las apuestas resultantes de estas acciones). Sería como si la dimensión moral del ser humano pudiese existir como una norma 
suprema a partir de la cual se deben definir acciones en detrimento de cualquier otro aspecto con menor valor comparativo ${ }^{(17)}$.

Según la directora general de Salud de Portugal, doctora Graça Freitas, la pregunta más difícil que los médicos pueden enfrentar en una pandemia es: ¿a quién debemos salvar y a quién no? Los economistas de la salud también analizan detenidamente la asignación de recursos de salud en los presupuestos gubernamentales. En general, no es extraño que haya ganadores y perdedores en estos cálculos, que algunos tratamientos sean cubiertos y otros no, aunque estos no siempre se puedan identificar individualmente.

Cualquiera sea el método utilizado para decidir quién vive o quién muere en esta pandemia, es duro asumir que, además del drama relacionado con el COVID-19 para los pacientes y los equipos que los tratan, también deben considerarse los dilemas éticos vinculados con las condiciones de trabajo de los cuidadores, atravesados por precariedades que los exponen al riesgo de enfermar ${ }^{(18)}$.

\section{Cuando la realidad imita la ficción}

¿Qué quiere decir en epidemiología la recurrente expresión "inmunidad colectiva"? Cuando la población es resistente a un germen, su propagación se detiene naturalmente porque no hay suficientes personas para transmitirlo. Así, el "rebaño" se inmuniza, aunque muchas personas dentro de él puedan aún ser afectadas. Ahora enfrentar la posibilidad de que miles de millones de personas sean infectadas con el coronavirus, cuya tasa de mortalidad estimada por infección es de alrededor del $1 \%$ puede ser terrible ${ }^{(19)}$.

$\mathrm{Si}$ el virus SARS-CoV-2 continúa propagándose, muchas personas se habrán infectado y (si sobreviven) se volverán inmunes. Esto hará que el brote se desvanezca por sí solo ya que para el germen será cada vez más difícil encontrar un huésped susceptible. La inmunidad colectiva no es más que esto. La amplia y continua propagación del coronavirus es exactamente el resultado que los expertos están modelando en sus peores escenarios. Dicen que, dado lo que saben sobre el virus, podría terminar infectando alrededor del $60 \%$ de la población mundial en un año. Las vacunas también crean otra forma de inmunidad colectiva cuando se administran ampliamente $\mathrm{o}$, a veces, cuando se administran en un "anillo" alrededor de un nuevo caso de infección.

Debe tenerse en cuenta que el coronavirus es un nuevo microorganismo, por lo que no parece que nadie sea inmune a él. Esto es lo que le permite propagarse y tener efectos tan graves en algunas personas. Para que funcione la inmunidad colectiva, las personas deben volverse resistentes una vez que están infectadas. Esto ocurre con muchos gérmenes: las personas infectadas y en recuperación se vuelven resistentes a contraer la enfermedad nuevamente, porque su sistema inmunitario está cargado de anticuerpos capaces de derrotarla.

Es esclarecedor saber que el punto en el que alcanzamos la inmunidad de rebaño está matemáticamente relacionado con la propensión de propagación del germen, expresada como su número de reproducción o R0. Los científicos estiman que el R0 para el coronavirus se encuentra entre 2 y 2,5 ; esto significa que, sin medidas para contener el contagio, cada persona infectada puede transmitirlo a otras dos personas.

Para imaginar cómo funciona la inmunidad colectiva, pensemos en los casos de coronavirus que se multiplican en una población susceptible de esta manera: 1, 2, 4, 8 , 16, y así sucesivamente. Ahora si la mitad de las personas son inmunes, la mitad de estas infecciones nunca sucederán, por lo que la velocidad de propagación se reduce efectivamente en dos. En este caso, según el Science Media Center, el brote se reproduce así: 1, 1, $1,1 \ldots$ y desaparece cuando la tasa de infección es inferior a 1.

La tasa actual de propagación del germen es más alta que la de la gripe común, pero similar a la de otras gripes que ocasionalmente existieron antes.

Esto es similar a la gripe pandémica de 1918. De acuerdo con este antecedente, 
el final de esta epidemia requerirá que casi el $50 \%$ de la población sea inmunice, ya sea gracias a una vacuna que no está en el horizonte inmediato, o como consecuencia de una infección natural. ${ }^{(19)}$

De esta manera, si el coronavirus se propaga más fácilmente de lo que piensan los expertos, más personas necesitarán contraerlo antes de que se logre la inmunidad del rebaño. Para un R0 de 3, por ejemplo, el $66 \%$ de la población tiene que ser inmune antes de que comience el efecto, según el modelo más simple. Ya sea $50 \%$ o $60 \%$ u $80 \%$, estos números significan miles de millones de infectados y millones de muertos en todo el mundo, aunque cuanto más lentamente se desarrolle la pandemia, mayores serán las posibilidades de que nuevos tratamientos o vacunas ayuden a mitigarla ${ }^{(19)}$. Ahora según los últimos modelos matemáticos, pasar a la inmunidad colectiva sería una estrategia desastrosa. Esto se debe a que muchas personas se enfermarán gravemente, y un aumento repentino de personas enfermas abrumará la atención hospitalaria o las Unidades de Cuidados Intensivos.

No podría faltar el uso de la idea de guerra contra el COVID-19, lógicamente. Sin embargo, que nuestras vidas atraviesen una grave pandemia ¿significa iniciar una guerra? Hasta cierto punto, no se puede negar que hay similitudes, pues justifica que se instalen regímenes de defensa y protección que alteran la vida cotidiana de las personas a gran escala, tal como ocurre en los conflictos bélicos que amenazan la integridad de los individuos que deben protegerse adecuadamente. Además, se generan reacciones similares a la de los individuos que sienten miedo, pánico, y manifestaciones psicosomáticas asociadas. Quien puede ser afectado por el COVID-19, tiene miedo.

Sin embargo, no se puede descartar que esta es una cuestión capaz de invocar figuras retóricas convenientemente ambiguas. Tal vez existan similitudes que permiten establecer lecturas de la "realidad" que sustentan ciertas posiciones políticas en detrimento de otras a través de distintos formatos "hermenéuticos".

Ciertas maniobras políticas muñidas del uso de la fuerza (generalmente militares) que generan una ruptura con el régimen constitucional deben ser literalmente denominadas con el término "golpe" o, en determinadas circunstancias, digamos maquiavélicas, también se puede producir un golpe sin romper con la estructura legal basada en la Constitución. En estas circunstancias, la expresión en inglés "lawfare" designa un uso abusivo de las normas jurídicas con fines políticos. Hay leyes que se instituyen bajo la tutela de asambleas con representantes que defienden intereses particulares, así como magistrados designados por los poderes políticos, que desarrollan interpretaciones interesadas políticamente de leyes que, a su vez, pueden ser sancionadas por asambleas parlamentarias cuyos representantes también defienden intereses particulares.

En el caso de la "guerra contra las drogas", la "guerra contra la pobreza", la "guerra contra el terrorismo", la "guerra contra entidades diabólicas", la "guerra contra el sida" y otros "frentes de batalla" es muy probable que el uso de metáforas esconda otros intereses o incluso prejuicios. Así, los caminos considerados democráticos eventualmente se distorsionan y comienzan a sufrir "desviaciones de funciones" con gobernantes populistas especialmente dañinos. Además, hay aspectos que deben tenerse en cuenta, como enfatiza Lucía Guimarães: no se trata realmente de una confrontación entre grupos humanos o naciones, sino de algo que también, para bien o para mal, emplea un tropo: la lucha por la supervivencia ${ }^{(20)}$. Finalmente, además de la metáfora de la guerra, nos enfrentamos a dos tropos más poderosos sobre la pandemia del SARS-CoV-2: la segregación y la racionalidad del mercado.

Existe el peligro de que tal instrumentalización del virus a través de las alegorías mencionadas sea capaz de fortalecer el nacionalismo, el racismo, la xenofobia, la precariedad económica, la desigualdad social y la racionalidad del capitalismo (con asombrosas excepciones). Por lo tanto, es posible construir bloques híbridos de espacios confinados para la experimentación de una biopsiconecropolítica.

Destacamos la importancia de las figuras retóricas con las que se representan 
enfermedades graves, puesto que una de las lecciones más brutales que hemos aprendido de la pandemia de sida es que estas metáforas también tienen el poder de matar. Por lo tanto, no es absurdo pensar que las manifestaciones retóricas son reveladoras de la forma en que se piensa y que se actúa. Esto sería destacable, especialmente, en los flujos cada vez más acelerados del capitalismo financiero y su producción de inequidades y el fracaso de los proyectos políticos de las izquierdas.

El único debate relevante parece centrarse en cómo aliviar gradualmente las medidas de aislamiento. ¿Se alterarán, hasta cierto punto, las reformas predominantes de las políticas adoptadas en las últimas cuatro décadas?, ¿asumirán los Estados un lugar menos "mínimo" en la economía?, ¿considerarán los servicios públicos como inversiones en lugar de gastos?, ¿se abandonará el mantra que subraya la "ineficiencia" de las empresas públicas en comparación con las privadas?, ¿se cuestionará la redistribución de la renta al igual que los privilegios de los más ricos?, ¿se adoptará políticas consideradas "descabelladas" como el ingreso básico ciudadano y el impuesto a las grandes fortunas?

Por muy bienvenidas que sean algunas predicciones y propuestas, son excesivamente modestas. Se necesita mucho más que eso. Es primordial superar la lógica de la rentabilidad y el crecimiento económico continuo y considerar las posibilidades de movilizar todos recursos disponibles en una sociedad para evitar tantas y tan profundas inequidades. Se debe dar prioridad a la atención médica, a la ecología global, a la producción y a la distribución de alimentos, al suministro de agua y electricidad, a los servicios de Internet y telefónicos. Si los recursos están disponibles, hay que asignarlos directamente, externamente a la lógica del mercado ${ }^{(21)}$.

\section{GAIA Y EL FIN DEL MUNDO}

Isabelle Stengers ${ }^{(22)}$ formula una conceptualización sobre la irrupción de Gaia, personificación mítica que retorna a nuestro planeta como consecuencia de un supuesto erróneo de los seres humanos: haber considerado al planeta como una fuente copiosa e inagotable de recursos naturales que podrían ser extraídos indefinidamente. En un texto originalmente escrito en 2009, en el marco de la crisis económica estadounidense iniciada en 2008, la pensadora belga menciona que al nombrar de esa forma a Gaia (Gea), los desastres que se anuncian (y ocurren a partir de la pandemia) se caracterizan como una intromisión.

Debe señalarse aquí una operación pragmática: nombrar no es enunciar la verdad. Sin embargo, el acto de nombrar nos permite sentir y pensar a partir de lo que se evoca al nominar (este es uno de los papeles de los ensayos). En nuestro caso, se trata de resistir la tentación de reducir a un simple "problema" un acontecimiento como el COVID-19. Aquí, por lo tanto, Gaia no es la Tierra "concreta" que se nombra y se invoca cuando se trata de afirmar nuestra conexión con el planeta del que extraemos recursos para la vida, la lucha y el pensamiento. Lo que estamos pensando es la intrusión, no pertinencia.

Si nombrar es operar y no definir, es decir, apropiarse, el nombre sin duda no puede ser arbitrario. En el siglo XX, este nombre tenía puntos de contacto, en primer lugar, con una propuesta de origen científico. Es decir, transmitir la necesidad de resistir a la tentación de una oposición brutal entre las ciencias y los sabres considerados "no científicos". Tal acoplamiento resulta necesario si queremos aprender a dar respuesta a versiones épicas de la historia humana: cuando el Hombre, erguido sobre sus dos piernas aprendió a descifrar científicamente las "leyes de la naturaleza", asumió a partir de ellas que era el dueño de su destino, libre de toda trascendencia.

Uno de los signos del regreso de Gaia, en términos generales, habría sido la relación abusiva de los seres humanos con el planeta en el que habitan. Parece, alegóricamente, que este lugar, Ilamado así por una entidad designada por Gaia, se manifiesta cada vez más. Y aunque haya personas con insignias académicas y políticas que argumenten que estas variaciones son "normales" 
si se observan en una escala de tiempo más amplia:

...en los últimos 500.000 millones de años, la vida en la Tierra casi fue aniquilada cinco veces, por cosas como el cambio climático, una edad de hielo intensa, volcanes y esa roca espacial que hace 65 millones de años se estrelló en el Golfo de México, exterminando a los dinosaurios y una gran cantidad de otras especies. Esos eventos se conocen como las cinco grandes extinciones en masa y todas las señales sugieren que ahora nos encontramos al borde de una sexta. Excepto esta vez, no será culpa de nadie sino de nosotros mismos. [...] la tasa de extinción actual podría ser 100 veces más alta de la normal y eso es solo si consideramos las clases de animales que conocemos más. Los océanos y los bosques de la Tierra albergan una cantidad incalculable de especies, muchas de las cuales probablemente desaparecerán antes de que siquiera las conozcamos. ${ }^{(23)}$

Este tema es tratado por Elizabeth Kolbert en su libro A sexta extinção: Uma história não natura ${ }^{(24)}$. En una entrevista a la autora, Nadia Drake formula las siguientes preguntas: ¿Qué pueden revelar estos nuevos resultados sobre el futuro de la vida en este planeta? ¿Hay alguna posibilidad de detener esta gran pérdida de vidas? ¿Están los humanos destinados a ser víctimas de su propia imprudencia ambiental? ¿Hay algún hábitats o especie o grupos de animales que sean especialmente vulnerables a los cambios que se están produciendo? A lo que Kolbert respondió:

Lo que está claro, y más allá de toda discusión, es que vivimos en una época en la que la tasa de extinción es elevadísima, del orden que podríamos observar durante una extinción masiva, aunque una extinción masiva puede tardar muchos miles de años en desarrollarse. [...] No creo que haya ninguna duda de que somos los responsables del elevado ritmo de extinción actual.
Muy pocas de las extinciones de los últimos cien años, por no decir ninguna, se habrían producido sin la actividad humana [...] Hay miles y miles de artículos científicos sobre eso. La hemos cargado sencillamente cazando. Hemos importado especies invasoras. Ahora estamos cambiando el clima, extremadamente rápido según el estándar geológico. Estamos cambiando la composición química de los océanos, estamos cambiando la superficie del planeta, talamos bosques, plantamos monocultivos, algo malo para muchas especies. Sobreexplotación pesquera [...] Si a una especie vertebrada (y nosotros somos una de ellas) le calculamos una vida media de un millón de años, y pensamos que el ser humano ha vivido doscientos mil años de ese millón, y precipitamos una extinción masiva (aun dejando a un lado la cuestión de si el ser humano será víctima de su propia extinción masiva) no podemos esperar que sigan existiendo las mismas especies cuando el planeta se haya recuperado. ${ }^{(23)}$

Ahora bien, ¿solo porque hemos sobrevivido a la pérdida de un número indefinido de especies consideramos que es posible continuar por el mismo camino?, ¿esto no conduce a agotar los sistemas que posibilitan la vida de las personas? E incluso si logramos sobrevivir, ies el mundo en el que deseamos vivir?, ¿es en este mundo que queremos que vivan todas las generaciones futuras de humanos? ${ }^{(23)}$.

En este sentido, y desde una perspectiva crítica, vale la pena sintetizar las ideas que la canadiense Naomi Klein desarrolla sobre la crisis ambiental en su libro Esto lo cambia todo: Capitalismo contra el clima ${ }^{(25)}$. Una de las cuestiones principales que allí se analizan son las relaciones entre capitalismo y cambio climático. Klein considera que la mayoría de la gente piensa que no se han tomado las medidas necesarias para reducir las emisiones industriales que provocan el cambio climático, aunque estas acciones esencialmente entran en conflicto con la noción de 
capitalismo desregulado vigente. Entonces, es necesario formular algunas preguntas ineludibles: ¿es esta la dirección correcta para nuestro futuro? Además, ¿quiénes están autorizados a dar una repuesta?, ¿los cara pálida? y, en este contexto, ¿qué es lo mejor que podemos hacer? La perspectiva de Klein para responder a estas inquietudes se basa en una idea de justicia social y ambiental según la cual la base del problema está en corregir las acciones humanas equivocadas que contribuyen a esto.

Klein analiza los problemas relacionados con la extracción de combustibles fósiles, las desigualdades socioeconómicas, los negadores del cambio climático y sus fuertes lazos conservadores y reaccionarios, y el comercio, desvinculados de principios ético y de flujos de capital. La autora señala que puede haber esperanza de cambio si las personas actúan de manera diferente a los patrones dañinos que se observan en todas estas actividades. Sugiere además que las respuestas a estos problemas requieren transformaciones sociales como la propiedad pública de los servicios de energía, transporte y agua. $\mathrm{Si}$ bien admite que no dispone de conocimientos técnicos basados en las ciencias ambientales, destaca la necesidad de enfrentar los imperativos de un capitalismo que postula sin vergüenza: "crecer o morir". Desde este precepto, el capitalismo bajo el sistema actual no está funcionando.

El libro también cierra filas con los críticos del cambio climático, la pobreza y el modo de desarrollo imperante. Sus argumentos sobre la justicia socioambiental se presentan en la segunda parte del trabajo. Allí se discuten temas controvertidos como las transferencias de riqueza y mecanismos redistributivos de financiamiento climático. Klein señala las deficiencias de la falsa dicotomía entre generación de empleo y crecimiento económico. Lo que realmente importa es la búsqueda de formas positivas de reinvertir en negocios socialmente equitativos y descree de cualquier propuesta que no aborde los orígenes reales de la pobreza.

Klein discute, además, la conexión entre el consumo y el cambio climático, des- tacando precisamente el aumento de las emisiones de China debido a su producción de bienes consumidos por el mundo occidental. En su argumentación critica el "consumo desperdiciado" y menciona la posibilidad de un "decrecimiento selectivo". Destaca que ya en 2014 había un diagnóstico de un statu quo del cambio climático distópico, sostenido por un "capitalismo de desastre" que habría ingresado a una "zona de sacrificio". Aun así, para evitar el pesimismo, señala que los movimientos de justicia climática y movilización social aún pueden ofrecer un futuro alternativo ${ }^{(26)}$.

En un artículo sobre la pandemia ${ }^{(27)}$, Klein comenta que estamos frente al mundo deseado por Silicon Valley, aunque esa no sea la forma en que queremos vivir. No queremos que nuestras vidas personales sean investigadas. Creo que, en cierto modo, deberíamos ver esto como una oportunidad para rechazar ese futuro al salir de esta crisis. Las personas usan las redes sociales, pero no podemos confiar en ellas para organizar una resistencia real, porque los ataques vendrán y tenemos que estar preparados para eso. Podemos ver que las grotescas divisiones económicas se amplían aún más. Estamos tratando de lidiar con los impactos de esta pandemia dentro de los escombros de las políticas de austeridad y creciente aniquilación de las normas laborales que la crisis hipotecaria ha generado a nivel planetario ${ }^{(27)}$.

Nombrar a Gaia como "la que hace la intrusión" también es caracterizarla como ciega, en términos de todos los destrozos que provoca. Por lo tanto, la respuesta que debemos crear no es una "respuesta a Gaia", sino una respuesta tanto a lo que causó la intrusión como a sus consecuencias.

\section{El carro de Jagannath}

Se ha dicho que el controvertido pensador británico Anthony Giddens entró en un cierto ostracismo académico, entre 1997 y 2007, después de colaborar con el gobierno de Tony Blair, primer ministro inglés. Aun así, en su libro Consecuencias de la modernidad 
ofrece una alegoría persuasiva. Se refiere al "carro de Juggernaut", una entidad basada en la deidad Vishnu que conduce un vehículo en una trayectoria "desbocada" ante la cual los devotos se arrojan bajo sus ruedas para ser atropellados en cultos místicos. El término proviene del indio Jagannath, que significa "señor del mundo", que a su vez deriva del sánscrito jagati que significa "él va" y natha es decir "maestro"(28).

Giddens lo relaciona con el descontrol/ hybris, que se observa en el funcionamiento errático de la llamada "modernidad". Nuestra existencia nos ubica a merced de los azares, sortilegios y peligros que conduce a una riesgosa pérdida de control sobre el devenir. Esta situación afecta intensamente el medio ambiente y las condiciones de vida. Juggernaut significa fuerza o una organización grande, pesada y poderosa que no se puede detener ${ }^{(28)}$.

En el libro primero de El Capital, Marx sostiene que:

...dentro del sistema capitalista todos los métodos para acrecentar la fuerza productiva social del trabajo se aplican a expensas del obrero individual; todos los métodos para desarrollar la producción se trastruecan en medios de dominación y explotación del productor, mutilan al obrero convirtiéndolo en un hombre fraccionado, lo degradan a la condición de apéndice de la máquina, mediante la tortura del trabajo aniquilan el contenido de éste, le enajenan -al obrero- las potencias espirituales del proceso laboral en la misma medida en que a dicho proceso se incorpora la ciencia como potencia autónoma, vuelven constantemente anormales las condiciones bajo las cuales trabaja, lo someten durante el proceso de trabajo al más mezquino y odioso de los despotismos, transforman el tiempo de su vida en tiempo de trabajo, arrojan su mujer y su prole bajo la rueda de Zhaganat del capital. ${ }^{(29)}$
Pero si navegar es preciso y la vida imprecisa, tenemos que adaptar el conocido aforismo "el que las hace, las paga" y considerar los modos en que nuestros recursos científicos y tecnológicos, construidos bajo la primacía de la precisión, son capaces de lidiar ante esta irrupción de Gaia, cuyos efectos no podemos precisar. Por lo tanto, es necesario volver a la cuestión de la esperanza. Y esto nos lleva justamente a repensar imperiosamente la existencia humana dentro de nuestras formas de vida en términos sociales.

En vista de este problema, el colectivo chino Chuang -integrado por comunistas que critican tanto el "capitalismo de Estado" del Partido Comunista Chino, como la visión neoliberal y prejuiciosa en términos étnicos de los movimientos de "liberación" de Hong Kong- destaca el potencial didáctico de la pandemia: se trata de un acontecimiento que nos obliga a pensar las formas en que la producción capitalista interactúa con el mundo no humano, puesto que en este mundo no se puede entender lo microbiológico sin referirse a las formas en que la sociedad ordena sus actividades productivas.

Es importante enfatizar que el virus SARS-CoV-2 fue, como el SARS-CoV 2003, el virus de la gripe aviar y el virus de la gripe porcina anterior, generado a partir de un conocido nexo entre la economía y la epidemiología. Ahora, como en otras configuraciones epidemiológicas, el salto del virus de una especie al ser humano está condicionado por la proximidad y la regularidad de este contacto. Cuando la interfaz entre humanos y animales cambia, también cambian las condiciones bajo las cuales evolucionan estas enfermedades. El papel de este entorno evolutivo creado por la agricultura capitalista y la urbanización es crucial, puesto que crea un medio óptimo para que las plagas devastadoras se muevan de una especie a otra y terminen convirtiéndose en vectores agresivos para la población humana.

Es necesario incluir procesos igualmente intensivos que tienen lugar en las fronteras económicas, en las que las cepas "salvajes" entran en contacto con individuos obligados a hacer incursiones agroeconómicas cerca 
de ecosistemas que aún no han sido explorados. El origen y los efectos de propagación del SARS-CoV-2 en el centro de un núcleo altamente urbanizado e industrializado de la economía global como Wuhan representan las dos dimensiones de esta era de plagas políticas y económicas.

En medio de la pandemia del COVID-19, es posible imaginar las razones de sus orígenes. Si el SARS-CoV-2 se ha adaptado previamente a otra especie animal, existe el riesgo de una recurrencia de eventos similares. Una comprensión detallada del modo en que un virus ha saltado entre especies para infectar a los humanos de manera tan efectiva debería ayudar a prevenir futuros eventos zoonóticos.

A su vez, si el proceso adaptativo ocurrió en humanos, incluso si se producen transferencias zoonóticas repetidas, es poco probable que el virus salte sin la misma secuencia de mutaciones. Además, la identificación de los parientes virales más cercanos del SARSCoV-2 que circulan en los animales será de gran ayuda. De hecho, la disponibilidad de la secuencia de murciélagos RaTG13 ayudó a revelar sus mutaciones principales, entre otros aspectos. Las características genómicas descritas aquí pueden explicar, en parte, la infecciosidad y la transmisibilidad del SARS-CoV-2 en humanos. Aunque la evidencia muestra que el SARS-CoV-2 no es un virus manipulado deliberadamente, actualmente es imposible probar o refutar otras teorías sobre su origen. Sin embargo, dado que hemos observado en la naturaleza todas las características notables del SARS-CoV-2 en coronavirus relacionados, no creemos que ningún tipo de escenario de laboratorio sea plausible.

Además, sería útil obtener más datos genéticos y funcionales sobre el SARS-CoV-2, incluidos los estudios en animales. La identificación de un posible huésped intermedio de SARS-CoV-2, así como la secuenciación del virus a partir de casos muy tempranos, también resultaría esclarecedor. Independientemente de los mecanismos exactos por los cuales el SARS-CoV-2 se originó, la vigilancia continua de la neumonía en humanos y otros animales es de suma importancia( ${ }^{(30)}$.
Otro aspecto extremadamente relevante es la desinversión masiva de los servicios públicos de salud y su reemplazo por servicios privados. Este contexto permite comprender algunas razones por las que el COVID-19 se propagó tan fácilmente. En este sentido, cabe destacar que en China aparece una enfermedad transmisible cada uno o dos años. $\mathrm{Y}$ sabemos que las condiciones parecen estar dadas para que estas epidemias no se detengan, como en el caso de la gripe española, las condiciones de salud pública generalmente pobres entre la población proletaria ayudaron a que el virus tomara forma $y$, a partir de ahí, se extendiera rápidamente ${ }^{(31)}$.

Žižek, en su texto “ $¡ B i e n v e n i d o$ al desierto de lo viral! Coronavirus y la reinvención del comunismo"(32), en forma alegórica, imagina la existencia de un virus ideológico benigno: uno que sea capaz de hacer que la gente piense en otras posibilidades de configuración de la sociedad, además del Estado-nación, que nos proyecte a nuevas formas de cooperación y solidaridad en términos globales. Como si no fuese posible seguir un modelo que produjera tanta inequidad, llega a la conclusión de que el cambio radical es imperativo.

Vale la pena explorar más este tema: cuando se supere esta pandemia, no tendremos forma de saber cuáles pueden ser las consecuencias en varios aspectos de la vida cotidiana (volveremos sobre esto al final). Por supuesto, otras pandemias pueden venir y esta dejará sus huellas. ¿Habrá una expansión intensiva de actividades digitales desde el hogar en aquellos privilegiados que tendrían acceso a ellas como uno de los efectos de la cuarentena en el mundo del trabajo? Por otro lado, ¿hay posibilidades para establecer diferentes vínculos de cooperación, no solo dentro de la familia, sino también en las relaciones interpersonales?, ¿ es posible construirlos con tensiones identitarias? ¿Será posible desarmar gradualmente los mecanismos del capitalismo financiero trasnacional y la precariedad generada por el ultraliberalismo? ¿Habrá un debilitamiento o fortalecimiento de las políticas regresivas y autoritarias que impulsan las extremas derechas? Sobre estos temas abundan las especulaciones. 
De hecho, este es un síntoma que evidencia la necesidad flagrante de remodelar la economía globalizada, que apunte a librarla de los caprichos inestables del mercado. Una forma de organización global capaz tanto de regular la economía como de limitar las relaciones peligrosas y espurias entre transnacionales "análogas" -índice Dow Jones Industrial Average (DJIA) ${ }^{(33)}-$, las empresas de tecnologías digitales -National Association of Securities Dealers Automated Quotations (Nasdaq)- y las poblaciones que componen lo que aún podríamos llamar "Estados-nación".

En otro texto, Žižek aborda cierto aspecto del SARS-COVID-2 con una alta sintonía con algunos extractos presentados en la introducción ${ }^{(34)}$. Allí, subraya que el coronavirus está constituido en un filamento de ARN, que parece tener un impulso reproductor compulsivo sin el cual no estaría vivo, es decir, estaría en el orden de los muertos vivos. Tal vez podríamos pensar este virus como "mega hordas" de venenosos nano-zombies, ávidos de tejido pulmonar humano. Sin embargo, no pueden considerarse como una forma primaria de vida, sino esencialmente como parásitos. Cuando nos infectan, solo somos parte de su ciclo de vida-muerte ${ }^{(35)}$.

\section{El estado de excepción que establece la regla inmunológica}

El psicoanalista y pensador Contardo Calligaris, en su columna habitual publicada en el diario Folha de São Paulo, cita al filósofo Giorgio Agamben, quien escribió breves textos sobre las medidas de confinamiento adoptadas para prevenir la expansión de la pandemia. Su idea era mostrar ciertos aspectos agambemianos en el sentido de que cualquier poder, siempre se inclina hacia un control cada vez más intenso y específico.

En este sentido, plantea una cuestión paradójica: la medicina (sería más correcto referirse a las ciencias y disciplinas de la salud y su promoción) se ha convertido en el representante de lo que podría ser el valor supremo para los seres humanos, puesto que intenta prolongar la vida al máximo posible a partir del desarrollo de conocimientos científicos y tecnológicos. Desde este poder, tiene la legitimidad para exigir que las personas -siempre que puedan emprender esta misión- acepten exigencias morales capaces de limitar la libertad individual y adoptar incondicionalmente prácticas de saludables -incluso abusivas- con miras a lograr la "eternidad".

En el caso de la pandemia, las amenazas son innegablemente reales y las medidas a distancia, justificadas. Aun así, según Calligaris, para Agamben podrían ser el fundamento de políticas restrictivas de la libertad. Ahora, está inconmensurablemente alejada la posibilidad de que Bolsonaro haya cambiado a su "gurú" -el filósofo Olavo de Carvalho- por Giorgio Agamben al intentar ejercer un contrapoder frente a las prescripciones epidemiológicas, en el sentido de flexibilizar las normativas que restringen la libertad de la población.

La cuarentena parece ser un asunto importante frente a este retorno de una represión pestilente, aunque no tiene sentido polemizar sobre este punto. El tema de Agamben es el "estado de excepción". En las circunstancias que atraviesa Brasil hoy, ya existe un estado de calamidad que, de acuerdo con el curso de la pandemia, puede incluso desembocar en un estado de sitio, si se produjeran "desórdenes" indeseables, algo que incluso podría producir el cierre del Congreso, de acuerdo con la virulencia presidencial.

En la comunidad filosófica, hubo debates y propuestas para suavizar la posición agambemiana. Pero, el punto presentado por CaIligaris recupera la existencia de dos tipos de libertad: la de hacer algo y la de deshacerse de algo indeseable. En términos más senciIlos, nunca debemos renunciar a la libertad que queremos vivir si esta renuncia se fundamenta en el miedo y las necesidades. En resumen: la cuarentena es aceptable en vista de las características epidemiológicas de la pandemia. No hay forma de confiar en un gobierno que defiende la flexibilidad frente a la pandemia cuando expresa explícita y simultáneamente sus nefastas inclinaciones totalitarias. 
De todos modos, es importante concebir, en resumen, el episodio COVID-19 a través del diagnóstico realizado por Van Loon $^{(36)}$ hace casi dos décadas: vivimos en un entorno apocalíptico en el que el miedo, la inseguridad y la sospecha se presentan simultáneamente con soluciones racionales para enfrentar las grandes contradicciones que enfrentamos. Estas paradojas, con propuestas de educación, capacitación, disciplina, vigilancia y control, incluyen deficiencias no asumidas. Con esta pandemia y sus dilemas, tenemos el paradigma inmune instituyéndose como una reacción, no como una acción. Es una contrafuerza que intenta, a pesar de sí misma, ser tan equivalente para evitar que otra fuerza actúe.

El dispositivo inmune actúa asumiendo la existencia del mal que se debe enfrentar. $Y$ no solo en el sentido de que su necesidad proviene de este mal, ya que el riesgo de la enfermedad justifica la acción preventiva y una epidemia transforma el contacto con otros como potencialmente riesgoso, sino también porque el sentido de su "existencia" se justifica por su propio uso. Y de esta manera, termina reproduciendo a escala controlada el mal que intenta evitar.

Inmune es aquel que está libre de obligaciones y cargos, es aquel que está exento. En definitiva, es un privilegiado. La inmunidad siempre es característica de alguien fuera de lo común. Es importante tener en cuenta que la inmunidad no solo significa exención de impuestos u obligaciones, sino una obliteración de las relaciones sociales en función de los pagos compartidos de la comunidad ${ }^{(37)}$.

Basado en Esposito, Paul Preciado sostiene que las políticas vinculadas con el COVID-19 son una forma de gestionar la vida y la muerte que delinea los contornos de una nueva subjetividad inmune. Desde esta perspectiva, lo que la crisis pudo haber instituido habría sido tanto una nueva utopía inmunológica como una nueva forma de configuración corporal(38).

David Harvey, un geógrafo estadounidense conocido por sus posiciones marxistas, formula una pregunta fundamental: ¿cuánto tiempo permanecerá esta situación de pandemia? Sugiere que su duración superará el año. Si fuera así, y si no hay intervenciones estatales que vayan en contra del espíritu neoliberal, el desempleo aumentaría a niveles equivalentes a los de la década de 1930, aunque las consecuencias inmediatas para la economía, así como para la vida social, serán diversas.

Ahora bien, no todos los efectos de la pandemia son necesariamente malos, ya que el excesivo consumismo contemporáneo estaba desempeñando un papel importante en la degradación del medio ambiente. Por ejemplo, la cancelación de vuelos aéreos y la reducción radical en el transporte y el movimiento han tenido consecuencias positivas en la reducción de las emisiones de gases. Además, por muy criticable que sea pensar sus efectos demográficos, el virus podría afectar a las pirámides de edad, con efectos tanto en los presupuestos de las jubilaciones como en el futuro de la "industria del cuidado". Por otro lado, es posible que el distanciamiento social produzca cambios culturales, aunque si ocurrieran, es difícil ponderar sus efectos ${ }^{(39)}$.

\section{Vacunación, aunque tarde}

Algunos expertos señalan que, en realidad, la gran apuesta debería ser el desarrollo de las vacunas, aunque su aplicación en masa pueda tardar más de 18 meses. El punto es que los virus son estructuras bioquímicas más rudimentarias que una célula viva. Por lo tanto, presentan menos sectores susceptibles como objetivos para la acción de drogas y además tienen una alta velocidad de replicación capaz de desarrollar rápidamente mecanismos de resistencia ${ }^{(40)}$.

The Washington Post, en su edición del 14 de abril de 2020, publicó un ranking de los peores gobiernos mundiales para hacer frente a la pandemia en sus países, ya que la gravedad del brote también depende de la acción de los gobiernos. Nicaragua, Turkmenistán y Bielorrusia se consideraron casos graves, pero por lejos, el caso más grave fue el gobierno brasileño. Como sabemos, Bolsonaro en un primer momento descalificó el 
coronavirus como una "gripecita" e instó a los brasileños a "enfrentar el virus como un hombre, no como un niño". Durante el inicio de la pandemia continuó haciendo campaña contra el distanciamiento social. Se necesitó una orden judicial para detener una campaña publicitaria que lanzó bajo el lema "Brasil no puede parar". Y hay evidencias de que Bolsonaro pudo haber sido infectado por el virus, sin enfermarse, y simplemente haber tenido una "gripecita". Si bien fue testeado por coronavirus, se negó a presentar el resultado, incluso bajo demanda parlamentaria. En sus apariciones públicas, aún no se abstiene de contactos poco cuidadosos con sus seguidores $^{(41)}$. A principios de julio, los periódicos brasileños informaron que Bolsonaro se había infectado de COVID-19. La evolución fue benigna. Por la televisión, atribuyó su recuperación al empleo de cloroquina, siguiendo el marco negacionista de su "política" de rasgos fascistas. El 25 de julio, un nuevo testeo dio resultado negativo. Nada mal para alguien que pertenece al grupo de riesgo de más de 60 años. De acuerdo a Bolsonaro, el hecho de haber sido atleta cuando era joven explica su resistencia.

De acuerdo con Bruno Latour -que juega para el equipo de Stengers- una vez que esta pandemia haya terminado, tendremos la posibilidad de repensar la economía e intentar que no adquiera nuevamente una dinámica predatoria con el medio ambiente. La irrupción de Gaia, como se dijo, representa una transformación ecológica que ya no se puede revertir. De hecho, ahí está la catástrofe ecológica covídica, aún capaz de exigir medidas de distanciamiento social junto con diversas medidas de cuarentena por dos años ${ }^{(42)}$. Pero no solo es esencial reconsiderar las formas en que la vida humana deberá funcionar a partir de ahora como parte del problema. Si es posible salir de la crisis pandémica, no se puede decir lo mismo de la crisis ambiental, cada una de ellas tiene especificidades, pero no es posible dejar de relacionarlas.

Uno no puede evitar asumir que una de las lecciones coronavirales más importantes es también la más sorprendente: se ha demostrado que es posible, en cuestión de semanas, suspender, casi simultáneamente en todo el mundo, un sistema económico globalizado que era considerado imposible de desacelerar o redirigir. Ahora sabemos que puede detenerse a pesar de las voces que se quejan al respecto. Era necesario que surgiera otro virus coronado para vincular a la especie humana en una globalización pandémica que se impuso inevitablemente a su dimensión económica. Sin embargo, los activistas neoliberales están ansiosos por enfrentar esta situación, incluso para deshacerse de lo que queda del Estado de bienestar y sus sistemas de seguridad social, de lo que queda de las regulaciones contra la contaminación y exterminar, descaradamente, a las poblaciones sobrantes de este mundo de Dios me libre.

El punto crucial que provoca la irrupción de este virus ARN no son solo las muertes que no cesan y que pueden continuar por un tiempo indefinible, sino las posibilidades de cristalizar una crítica al carácter inhumano del sistema económico. Si los índices económicos pierden el sentido de guiar las cosas de la vida, cada día de un presente sin síntomas tiene gran valor. Debemos vislumbrar que no se debe hacer todo lo que hemos hecho si no queremos ser reproductores de estas formas de co-vida ancladas en el movimiento de los mercados financieros y el sostenimiento de un crecimiento económico plagado de efectos adversos.

Efectivamente, nuestras vidas pueden describirse cada vez más como co-vidas a partir de la existencia del último coronavirus. Ciertamente, la posible alusión a lenguas de origen ibérico, en las que el prefijo "co" actúa como una abreviatura de "con" y "vid(a)", un prepositivo vinculado a "viv" (vivir, estar en la vida) ${ }^{(43)}$ es una mera coincidencia. Pero, en cualquier caso, la cuestión de la condición vital del nuevo coronavirus ya se está planteando. Debido a que es una molécula de ARN, la propiedad reproductiva parásita dentro de la célula humana no es suficiente para reconocerla como un organismo vivo. Curiosamente, uno de los significados del término parásito es "coexistir": se trata de algo que, según las circunstancias, considera que hay almuerzos gratis. Esta posición es 
aborrecida por aquellos que piensan que el Dios-mercado tendría algo asimilable a una "sabiduría" capaz de regular la co-vida humana, aunque no se puede culpar a este Dios por el estado de cosas pandemonial.

Incluso se puede considerar que el nuevo coronavirus tiene una "co-vida" cuando utiliza la maquinaria de reproducción de la célula humana. Esto no es algo ajeno a los seres humanos. De acuerdo con los contextos y los modos de vida, la humanidad fue instruida para adoptar prácticas inmunes de co-vida junto con diversos microorganismos. Ahora la co-vida en el contexto de esta pandemia, no siempre es posible para un gran contingente de personas que, afectadas por flujos de precariedad neoliberal, no pueden escapar a la situación de víctimas epidemiológicas de este evento calamitoso.

De hecho, es difícil dejar de lado la posibilidad de que la pandemia juegue un doble papel bajo el régimen dictatorial del capital. Por un lado, es la motivación perfecta para poner en práctica rápidamente un conjunto de medidas que no solo salven los procesos globales de apreciación de precios y acumulación de capital, sino que incluso los maximicen a futuro, como sucedería en una situación de guerra. Los despidos, los recortes salariales, los ahorros financieros o las medidas de austeridad están comenzando a implementarse en algunos países, solo que ahora están acompañados con un retorno cínico de discursos a favor del Estado de bienestar. Imaginemos un país en el que se instale la "bolsonarie" $"$ (44).

Parece que estamos viviendo un momento en el que debe postularse otro modo de producción y consumo menos disipativo, capaz de cuestionar sus premisas y efectos para combatir las terribles injusticias estructurales del "juego" dominante. Ahora no debemos resignarnos ante sentencias repetidas que expresan ciertos aspectos cínicos de sus manifestaciones tales como: "son cosas del juego".

¿Será diferente el mundo pospandémico? Ciertamente debería serlo. ¿Pero cómo? Difícil especular sobre eso. En cualquier caso, no es sorprendente que haya proyecciones futuristas que todavía respalden las premisas neoliberales. Los ejercicios de futurología siempre están sujetos a la inestabilidad. Aun así, es no es posible considerar que algo será como antes. Varios futurólogos dicen que el coronavirus actuará como un acelerador de lo que vendrá, aunque su foco no está en quienes se encuentran en las zonas más precarias de la configuración actual. La pandemia anticipará cambios que ya estarían en marcha, como el trabajo a distancia, la educación a distancia, la búsqueda de sustentabilidad y la demanda de empresas que sean realmente más responsables socialmente.

Serán deseables otros cambios, como el fortalecimiento de la solidaridad y la empatía, así como el cuestionamiento del modelo de sociedad basado en el consumo y las ganancias a cualquier costo. Aunque nada garantiza que estos cambios ocurrirán, las transformaciones deberían incluir la política, la economía, los modelos de negocios, las relaciones sociales, la cultura, la psicología social y la relación con la ciudad y el espacio público, entre otras cosas. Entonces, las supuestas tendencias para el mundo del consumidor pospandémico serían:

1. Revisión de creencias y valores: las crisis de este tamaño pueden hacer que las comunidades se unan y trabajen más como equipos, ya sea en los vecindarios, entre los empleados de las empresas, y esto puede afectar los valores de quienes tienen esta experiencia, como sucedió con las generaciones que vivieron las guerras.

2. Menos es más: la crisis financiera resultante de la pandemia por sí sola será una razón para que las personas ahorren más y revisen sus hábitos de consumo. En este mismo sentido, se espera un mayor cuestionamiento del capitalismo financiero. El coronavirus habría llevado al contexto comercial y personal la necesidad de revisar las prioridades. En una organización, lo que antes generaba resultados financieros como persuadir, alentar el consumo, aumentar la producción y las ventas, hoy ya no funcionaría.

3. Reconfiguración de espacios comerciales: habrá un aumento en la percepción 
de riesgos y peligros que podrán acentuar el miedo y la ansiedad. Por lo tanto, los cuidados de la salud deberán extenderse a lugares públicos, especialmente a los cerrados. Los sitios privados como bares, restaurantes, cafeterías, gimnasios y coworkings deberán rediseñar sus espacios para reducir el hacinamiento y facilitar el acceso a productos de higiene, como el alcohol en gel.

4. Nuevos modelos de negocio para establecimientos que trabajan solo con entregas: ante la posibilidad de nuevas olas de la pandemia en el futuro cercano, el sector de los restaurantes debe ser consciente de los cambios en su modelo de negocio. El servicio de entrega seguirá en aumento y puede convertirse en la principal fuente de ingresos en muchos casos.

5. Experiencias culturales inmersivas: en respuesta al aislamiento social, los artistas y los productores culturales están apostando por espectáculos en línea, así como las visitas virtuales a los museos. Este comportamiento debe evolucionar hacia lo que se puede Ilamar experiencias culturales inmersivas, que intentan conectar lo real con lo virtual a través del uso de tecnologías ya disponibles como la realidad virtual, los asistentes virtuales y las máquinas inteligentes.

6. Trabajo remoto: la oficina en el hogar ya era una realidad para muchas personas, desde autónomos y profesionales hasta empleados de empresas que ya habían adoptado el modelo. Pero esta modalidad crecerá aún más. Con la pandemia, más compañías comenzaron a organizarse para trabajar con este modelo. Además, el trabajo remoto evita la necesidad de estar en espacios abarrotados, como autobuses y metro, especialmente durante las horas pico.

7. Shopstreaming: con el aislamiento social, la vida explotó, especialmente en Instagram. Las ventas por Internet también se convierten en una opción para las tiendas que hasta entonces solo lo hacían desde una ubicación física. Si pensamos en la unión de las dos cosas tendemos el shopstreaming.
8. Búsqueda de nuevos conocimientos: actualizar el conocimiento es una cuestión de supervivencia en el mercado. Pero la era de incertidumbres que abrió la pandemia agudizó este anhelo en gente que, motivada por las circunstancias, consumen en forma creciente cursos on line. Muchos trabajos están desapareciendo, algunas actividades están perdiendo terreno, mientras que otros servicios ganan espacio en el mercado.

9. Educación a distancia: la expansión de la educación a distancia se acelera. En este contexto, una nueva figura debe entrar en consideración: mentores virtuales. Trend Watching apuesta a que surjan nuevas plataformas o servicios que conecten a mentores y maestros con personas que quieran aprender sobre diferentes temas ${ }^{(45)}$.

A continuación, se presentan tendencias de consumo emergentes de acuerdo con Trend Watching ${ }^{(46)}$ cada una ilustrada con un ejemplo reciente de innovación. Su objetivo es, por un lado, ofrecer señales tempranas de aquello que las personas valorarán y sus prioridades en un mundo posterior al coronavirus y, por el otro, lo que esta compañía tendría que ofrecer como consultoría.

- La economía basada en la experiencia virtual: las nuevas tecnologías inmersivas podrían conducir a las personas a obtener cambios de estatus a partir de experiencias virtuales como las expresiones en las redes sociales. Otras experiencias virtuales menos competitivas, como los "viajes", venta minorista, citas y más, podrán adquirir nuevas significaciones en este sentido.

- Soluciones open source: Ilaman a esta tendencia una "nueva frontera audaz para promover la sustentabilidad", el acto de compartir e incluso dar soluciones innovadoras a los problemas más difíciles compartidos. En este momento el coronavirus es el problema transnacional y transdemográfico más urgente en la historia reciente. Esto les recordará a las personas que las mejores organizaciones colaboran "generosamente" con los demás. 
- Bienestar ambiental: El uso de alcohol en gel es necesario ya que las personas lo necesitan para movilizarse en su vida cotidiana. Es posible que su demanda baje cuando pase el momento más crítico de la pandemia, pero el deseo de prevenir posibles infecciones permanecerá. Esto crea oportunidades para que los proveedores de espacio físico incorporen medidas de higiene para cuidar la salud de sus clientes.

- Compañeros virtuales: a medida que los consumidores se acostumbren a los asistentes digitales y chatbots, sus expectativas evolucionarán. Algunos comenzarán a buscar personalidades virtuales que tengan el poder de entretener, educar, hacer amigos y sanar. La crisis aumentará la demanda de estos compañeros virtuales.

- A-commerce: en 2017 y 2018, el desarroIlo de la inteligencia artificial fue el principal impulsor de esta tendencia. Ahora, el repentino aumento en la demanda de interacciones sin contacto que converge con los avances en robótica está permitiendo una nueva generación de comercio automatizado.

- El burnout: El coronavirus no es la única fuente de angustia contemporánea. Incluso antes de que se desencadene una crisis sanitaria y económica mundial, las personas enfrentaban desigualdades rampantes, disputas sociales, una inminente amenaza existencial provocada por la crisis climática y mucho más. No es sorprendente, por lo tanto, que cualquier organización que pueda ayudar a mejorar el bienestar mental de las personas sea bienvenida con los brazos abiertos.

- Desarrollo asistido: A muchos se les pedirá u obligará a aprender algunas habilidades domésticas, como cocinar por sí mismos. A los observadores de tendencias les encanta marcar estas cosas como propias de "millennials". A pesar del reciente crecimiento de la economía del delivery puede que algunos de ellos se vean obligados a abandonar este recurso cuando la crisis haya terminado.

- Símbolos de estatus virtual: Los activos físicos han tenido durante mucho tiempo el monopolio de la exhibición de su estado, pueden ser naturalmente escasos o caros. Los consumidores más jóvenes y los videogamers han utilizado durante mucho tiempo bienes virtuales. Como consecuencia del coronavirus se espera que las nuevas tecnologías y el creciente deseo de consumo sostenible converjan y promuevan el reconocimiento de los bienes virtuales como símbolos de estatus.

El periódico El País también realiza un intento oracular -parte del espíritu contemporáneopara anticipar posibles cambios económicos pospandémicos. Allí se destaca en resumen en el que cada crisis económica deja un legado de recuerdos, heridas y cambios. Es difícil pensar que esta experiencia inimaginable de tapabocas, máscaras, distanciamiento social, pérdidas humanas y cancelación de la vida no tendrá consecuencia después de la pandemia. Aún parece temprano anticipar exactamente cuáles. Los analistas pueden tomar años e incluso décadas para explicar todas las implicaciones de lo que se vive en estos días. La paradoja es que este virus explota las características de la vida que nos hemos dado: sobrepoblación, turismo masivo, grandes ciudades, viajes aéreos constantes, redes de suministro a miles de kilómetros de distancia y desigualdad extrema en el reparto de la riqueza y los sistemas de salud pública.

Las empresas han reparado en el riesgo que representa sumar dependencia y distancia. Sin embargo, las redes nacionales de producción también se paralizan ante una pandemia. Nada indica que la globalización se revertirá, aunque posiblemente haya rupturas. ¿Incluso con el capitalismo? Vale la pena considerarlo, porque su esencia es el movimiento constante de personas y bienes, las mismas características, mutatis mutandis, de la pandemia. Y, por otro lado, ¿qué respuestas sociales pueden darse, especialmente en los jóvenes, cuya única experiencia del capitalismo es una crisis? ¿Saldrán a las calles? Es muy temprano para saberlo. Sin embargo, los límites y las fronteras del mundo aparentemente formarán un entramado más fino y menos resistente. La conjunción del brexit, la 
epidemia y la guerra comercial entre China y EEUU anticipan años complicados en el futuro.

Además, en estos meses de pandemia, proliferan numerosos intérpretes y oráculos de la tragedia. Este es otro legado del virus: más trabajo en el hogar, auge de pagos electrónicos, mayores controles fronterizos, seguros costosos y complejos, educación y atención médica a distancia, menos viajes y menos convenciones internacionales. Pero, sobre todo, debemos pensar en cómo hacer que el sistema de salud sea más eficiente, porque al hacerlo se vuelve más viable y universal. Se trata de considerar la inclusión resolutiva de la telemedicina (con protocolos específicos, sin el análisis de costos y beneficios que empobrecen la relación entre médicos y pacientes), monitoreo de pacientes en el hogar luego de intervenciones quirúrgicas y tratamientos farmacológicas accesibles. Nada tan revolucionario, todo muy urgente.

En esta oscuridad terrestre, la única buena noticia parece ser la mitigación de la emergencia climática y ambiental. Este alivio es el beneficio colateral más evidente de la pandemia dantesca. Nos vimos obligados a cambiar nuestra vida cotidiana en un instante. Ahora, ies posible mantener, hasta cierto punto, la forma en que habitamos el planeta? Las decisiones que tomen los bancos centrales, los gobiernos y las instituciones financieras darán forma a nuestras sociedades en los años venideros. Es hora de movilizar recursos para priorizar la salud y el empleo de las personas. Además, los gobiernos deben invertir en reducir la dependencia de nuestras economías de los combustibles fósiles, así como del crecimiento infinito que continúa alimentando el desastre.

La superación de la pandemia dependerá de cómo se desarrolle el coronavirus y la respuesta del sistema de salud. Pero, incluso en el mejor de los casos, la situación será grave para los mercados emergentes. Antes de la crisis, ya presentaban una deuda externa muy alta y un crecimiento decreciente. Esto provocará el colapso de muchas naciones. Quizás se requiera una moratoria en el pago de las deudas púbicas de los países más afectados.
La pandemia pasará y será necesario pensar en qué calles y ciudades caminaremos, porque la Tierra está en peligro de caer en una especie de depresión social causada por este tiempo de distancia. Por último, es probable que concluyamos que muchos trabajos se pueden hacer en casa, ahorrando el tiempo y el combustible del viaje. Indudablemente, la inmensa urgencia del presente nos impide evaluar qué horizonte dejará el futuro ${ }^{(47)}$.

Si asumimos un enfoque más dark, podemos vernos como testigos de la sexta extinción de la vida terrestre. Esta crisis viral, posiblemente mucho más grave que otras que han amenazado en las últimas décadas, sería solo uno de los vectores apocalípticos: específicamente se trata de aquellos que logran traspasar las fronteras entre especies, generando invasores que entran en conflicto con otros organismos y sus mutaciones.

En mayo de 2020, la sinergia coronaropandemia y gobierno negacionista de extrema derecha que actúa como si sufriera demencia, empeora la situación del COVID-19 en Brasil. Medidas de aislamiento mitigadas, menos adherencia a ellas, subregistro, colapso sanitario en varios estados, muertes en aumento por COVID-19, nada parecido a "aplanar la curva". A principios de junio, el gobierno intentó cambiar el sistema de comunicación de datos epidemiológicos oficiales para dificultar la evaluación del desarrollo de la pandemia. Entonces, un grupo de periódicos brasileños influyentes decidió llegar a un acuerdo con los niveles regionales del sistema de información en salud para mantener la confiabilidad de los datos. Además, se descartaron dos médicos como ministros de Salud, en especial, por no estar de acuerdo con la recomendación oficial del empleo de cloroquina para tratar el COVID-19. En septiembre de 2020, el Ministerio estaba a cargo de un militar. Teniendo en cuenta la perspectiva de gestionar una política de vacunación masiva, también fue invitado un veterinario.

A inicios de septiembre, la situación de Brasil sigue siendo muy difícil. Los casos y las muertes se mantienen en un nivel alto. Ya se superaron las 120 mil muertes en el país. 
La autorización general de abrir la economía no ofrece perspectivas muy favorables. Y cuando calienta el sol aquí en la playa, mucha gente siente que sus cuerpos vibran. No son pocos los que deciden "si, vamos a la playa". Y desgraciadamente, bajo el espíritu de pandemencia de este ensayo, no tiene sentido poner un punto final

\section{REFERENCIAS BIBLIOGRÁFICAS}

1. Harrison S. Ask the Know-lt-Alls: What Is the Coronavirus? Wired [Internet]. 2020 [citado 20 mar 2020]. Disponible en: https://tinyurl.com/y22g6mm2.

2. Escobar P. China travou guerra híbrida com os Estados Unidos. Vermelho [Internet]. 2020 [citado 20 mar 2020]. Disponible en: https://tinyurl.com/yxz3tnm9.

3. Espinoza Pino M. COVID-19, el virus de la era neoliberal. La Vorágine [Internet]. 2020 [citado 15 abr 2020]. Disponible en: https://tinyurl.com/y2dhtmd8.

4. Butler J. Judith Butler sobre a Covid-19: O capitalismo tem seus limites. Blog Da Boitempo [Internet]. 2020 [citado 21 abr 2020]. Disponible en: https://tinyurl.com/ y45rpo9a.

5. Hodgson C. Verdadeira taxa de letalidade do novo coronavírus é mistério. Folha de S.Paulo [Internet]. 2020 [citado 31 mar 2020]. Disponible en: https://tinyurl.com/ qkkxwry.

6. Boghossian B. Bolsonaro e profetas da negação ignoram as vítimas do coronavírus. Folha de S.Paulo [Internet]. 2020 [citado 10 abr 2020]. Disponible en: https:// tinyurl.com/vsqdb7a.

7. Horton R. Offline: What have economists ever done for global health? The Lancet [Internet]. 2020 [citado 6 abr 2020]. Disponible en: https://tinyurl.com/y2pabuj7.

8. Magnoli D. Pandemia leva a guerra estúpida entre 'arautos da vida' e 'campeões da economia'. Folha de S.Paulo [Internet]. 2020 [citado 11 abr 2020]. Disponible en: https://tinyurl.com/sjwvh4r.

9. Beltrão H. O cálculo político do governador. Folha de S.Paulo [Internet]. 2020 [citado 24 abr 2020]. Disponible en: https://tinyurl.com/y9en8wdq.

10. Martins ACM, Braga MVA. O risco da subnotificação: População pode reduzir cuidado por desconhecer o real cenário da ameaça. Folha de S.Paulo [Internet]. 2020 [citado 3 abr 2020]. Disponible en: https://tinyurl.com/ y2hmszgy.

11. Kupferschmidt K. The lockdowns worked-but what comes next? Science. 2020;368(6488):218-219. doi: 10.1126/science.368.6488.218.

12. Canzian F. Atenção básica vê 'terceira onda' de doentes atingindo o sistema de saúde. Folha de S.Paulo
[Internet]. 2020 [citado 30 abr 2020]. Disponible en: https://tinyurl.com/y75o28ey.

13. Pondé LF. A afirmação de que vidas fazem a economia e não o contrário é conversa para Disneylândia. Folha de S.Paulo [Internet]. 2020 [citado 21 abr 2020]. Disponible en: https://tinyurl.com/y5qhchn4.

14. Ferrater-Mora J. Diccionario de Filosofía. Madrid: Alianza Editorial; 1986.

15. Magnelli A, Maia F. "Precisamos agir com o saber explícito de nosso não-saber": entrevista com Jürgen Habermas. Ateliê de Humanidades [Internet]. 2020 [citado 15 abr 2020]. Disponible en: https://tinyurl.com/vowlvxj.

16. Austin MW. What's Wrong With Utilitarianism? Psychology Today [Internet]. 2020 [citado 20 abr 2020]. Disponible en: https://tinyurl.com/yb6jmmx7.

17. Frakt A. Who Should Be Saved First? Experts Offer Ethical Guidance. The New York Times [Internet]. 2020 [citado 21 abr 2020]. Disponible en: https://tinyurl.com/ y5q2tozx.

18. Lopes MA. Quem vive e quem morre: dilemas éticos no surto da Covid-19. Observador [Internet]. 2020 [citado 5 abr 2020]. Disponible en: https://tinyurl.com/y6nn45oj.

19. Regalado A. What is herd immunity and can it stop the coronavirus? MIT Technology Review [Internet]. 2020 [citado 30 mar 2020]. Disponible en: https://tinyurl.com/ yasyt3h8.

20. Guimarães L. Metáfora da guerra não faz bem à saúde pública ou à democracia. Folha de S.Paulo [Internet] 2020 [citado 8 abr 2020]. Disponible en: https://tinyurl. com/vto5mrk.

21. ŽiŽek S. Mundo ameaçado por coronavírus não se parece com filmes apocalípticos de Hollywood, diz Zizek. Folha de S.Paulo [Internet]. 2020 [citado 22 abr 2020]. Disponible en: https://tinyurl.com/y3bvduoo.

22. Stengers I. En tiempos de catástrofes: Cómo resistir a la barbarie que viene. Barcelona: NED Ediciones; 2017.

23. Drake N. ¿Sobrevivirán los humanos a la sexta gran extinción? National Geographic [Internet]. 2017 [citado 22 abr 2020]. Disponible en: https://tinyurl.com/y2gbhls9.

24. Kolbert E. A sexta extinção: Uma história não natural. Rio de Janeiro: Intrínseca, 2015. 
25. Klein N. Tudo pode mudar: Capitalismo vs Clima. Barcarena: Editorial Presença, 2016.

26. Lester S. Book Review: This Changes Everything: Capitalism vs. The Climate by Naomi Klein. The London School of Economics and Political Science [Internet]. 2014 [citado 19 abr 2020]. Disponible en: https://tinyurl. com/y2fdpj5p.

27. Colón Núñez A. The coronavirus crisis is disaster capitalism in action: Here's how the left can respond. In These Times [Internet]. 2020 [citado 19 abr 2020]. Disponible en: https://tinyurl.com/y5e9neof.

28. Juggernaut. Macmillan Dictionary Blog [Internet]. 2020 [citado 26 mar 2020]. Disponible en: https://tinyurl. com/y6fcfa2c.

29. Marx K. El Capital: Libro primero, el proceso de producción del capital. T. 1. Vol III. 20a ed. México DF: Siglo Veintinuno Editores; 2005.

30. Andersen KG, Rambaut A, Lipkin WI, Holmes EC, Garry RF. The proximal origin of SARS-CoV-2. Nature Medicine. 2020;26:450-452. doi: 10.1038/s41591-0200820-9

31. Coletivo Chuang. Outras Fitas: Contágio Social - coronavírus, China, capitalismo tardio e o 'mundo natural'. A Fita [Internet]. 2020 [citado 29 mar 2020]. Disponible en: https://tinyurl.com/y5oege7o.

32. Žižek S. Žižek: Bem-vindo ao deserto do viral! Coronavírus e a reinvenção do comunismo. Blog Da Boitempo [Internet]. 2020 [citado 20 mar 2020]. Disponible en: https://tinyurl.com/y2n2sazl.

33. Índice Dow 30 (Dow 30). Capital.com [Internet]. 2020 [citado 20 mar 2020]. Disponible en: https://tinyurl. com/y44ha92q.

34. Žižek S. Žižek: Monitorar e punir? Sim, por favor! Tradutores Proletários [Internet]. 2020 [citado 29 mar 2020]. Disponible en: https://tinyurl.com/y5ke22tw.

35. Koshy Y. Pandemic! by Slavoj Žižek review - the philosopher provides his solution. The Guardian [Internet]. 2020 [citado 24 abr 2020]. Disponible en: https://tinyurl. com/y7wgf5d5.

36. Van Loon J. Risk and technological culture: towards a sociology of virulence. London: Routledge; 2002.
37. Esposito R. Immunitas: Protección y negación de la vida. Buenos Aires: Amorrortu; 2005

38. Agamben G, ŽiŽek S, Nancy JL, Berardi F, López Petit S, Butler J, Badiou A, Harvey D, et al. Sopa de Wuhan: Pensamiento contemporáneo en tiempos de pandemias [Internet]. 2020 [citado 4 abr 2020]. Disponible en: https://tinyurl.com/y7pwl245.

39. Harvey D. Anti-Capitalist Politics in the Time of COVID-19. Reading Marx's Capital with David Harvey [Internet]. 2020 [citado 12 abr 2020]. Disponible en: https://tinyurl.com/y4wwcagu.

40. Dias M. Nenhum remédio será cura para Covid-19; esperança é a vacina, diz cientista. Folha de S.Paulo [Internet]. 2020 [citado 20 abr 2020]. Disponible en: https:// tinyurl.com/yxj5syor.

41. The Washington Post. Leaders risk lives by minimizing the coronavirus: Bolsonaro is the worst. The Washington Post [Internet]. 2020 [citado 16 abr 2020]. Disponible en: https://tinyurl.com/tmjqlx9.

42. Lopes RJ. Por até dois anos, vamos ter de alternar períodos de abertura e quarentenas, diz Atila lamarino. Folha de S.Paulo [Internet]. 2020 [citado 4 abr 2020]. Disponible en: https://tinyurl.com/wwfokhz.

43. Houaiss A. Dicionário Houaiss da Língua Portuguesa. São Paulo: Editora Objetiva; 2001

44. Velasco Ortiz R. Amalgama de miradas apocaelípticas. La Vorágine [Internet]. 2020 [citado 4 abr 2020]. Disponible en: https://tinyurl.com/yy9xoy5w.

45. Melo C. Como o coronavírus vai mudar nossas vidas: dez tendências para o mundo pós-pandemia. El País [Internet]. 2020 [citado 18 abr 2020]. Disponible en: https:// tinyurl.com/y4mn5rpu.

46. Trend Watching. A post-Corona world: 10 emerging consumer trends that have been radically accelerated by the crisis [Internet]. 2020 [citado 18 abr 2020]. Disponible en: https://tinyurl.com/yyz9nymu.

47. García Vega MA. Como será a economia após o coronavírus. El País [Internet]. 2020 [citado 19 abr 2020]. Disponible en: https://tinyurl.com/y48t6zng. 